\title{
Asymmetric Snubberless Current-Fed Full-Bridge Isolated DC-DC Converters
}

\author{
Roman Kosenko* (Student Member, IEEE, Chernihiv State University of Technology, Chernihiv, Ukraine), \\ Andrei Blinov (Member, IEEE, Tallinn University of Technology, Tallinn, Estonia), \\ Dmitri Vinnikov (Senior Member, IEEE, Tallinn University of Technology, Tallinn, Estonia), \\ Andrii Chub (Member, IEEE, Chernihiv State Technological University, Chernihiv, Ukraine)
}

\begin{abstract}
This paper presents two isolated current-fed fullbridge DC-DC converters that can be used to interface a lower voltage source into a DC bus of higher voltage. The first topology uses a resonant circuit to force current redistribution between low-voltage-side transistors and a passive rectifier. The second topology utilizes an active rectifier with secondary modulation to achieve the same goal. The resonant circuit can be formed by using transformer leakage inductance and the parasitic capacitances of the switches. The converters feature soft switching of semiconductors over a wide range of operating conditions. This is achieved with decreased energy circulation when compared to existing topologies with symmetric control and with fewer semiconductors than in those with phase-shift control. The topologies can be implemented in renewable, supercapacitor, battery, fuel cell, and DC microgrid applications. Steady-state operation and design aspects of the converters are presented and verified experimentally with $400 \mathrm{~W}$ prototypes.
\end{abstract}

Keywords - DC-DC power converters; Soft switching; Zerocurrent switching; Zero-voltage switching.

\section{INTRODUCTION}

Power electronic systems with a variable gain are required to interface different renewable energy sources or storage systems into the microgrid [1]. Converters with transformers are often preferred due to reduced stresses on the components and better flexibility of application [2], [3]. A significant portion of the past and present research that is related to isolated DC-DC converters is focused on voltage-fed dualactive-bridge (DAB) topologies [4]-[6]. These converters feature good regulation capabilities and soft switching over a wide range of operating conditions with advanced multi-mode digital control algorithms. At the same time, isolated currentfed (CF) converters could be beneficial due to their inherent boost capability, low input current ripple, reduced energy circulation, reduced requirements regarding the isolation transformer and simpler control system [7]-[9]. The present study is focused on full-bridge-type topologies due to their flexibility and scalability, making them suitable for a wide range of applications with various voltage and power levels. A common drawback of isolated $\mathrm{CF}$ topologies is related to voltage overshoots across primary transistors due to the leakage inductance of practical transformers. This issue is usually solved by applying a RCD snubber [10], the active clamp circuit introduced in [11] or solutions without snubbers, by utilizing the parasitic parameters of the circuit [14]-[17]. The latter approach is advantageous due to the reduced number of components required and the soft switching provided for power switches in the topology.

Existing snubberless (also referred to as "clampless") converters can utilize the symmetric [12], [13] control algorithm or the phase-shift one [14]-[17]. In phase shift control, the primary switches need to have the reverseblocking capability. Given the typical realization of this function (with a series diode or an anti-series switch), it leads to a remarkable increase in the total number of primary semiconductors and their power losses. On the other hand, at some operating points, symmetric topologies have excessive energy circulation and increased current stress on the primary switches and the transformer. In addition to the existing solutions, the present paper proposes two asymmetric topologies that combine the properties of both approaches and could provide an improved weighted performance, particularly if the converters have to operate under a wide range of input voltage and power levels. In this paper, operation with a fullbridge rectifier is assumed; however, the voltage-doubler rectifier can be applied for both converters as well. The operation principle of the topologies is described in Section II, design guidelines are presented in Section III and the experimental results are demonstrated in Section IV.

* Corresponding author.

E-mail: roman.kosenko@ttu.ee 


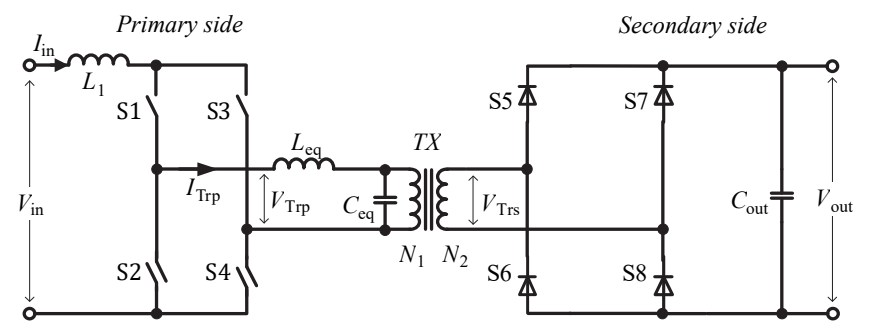

a)

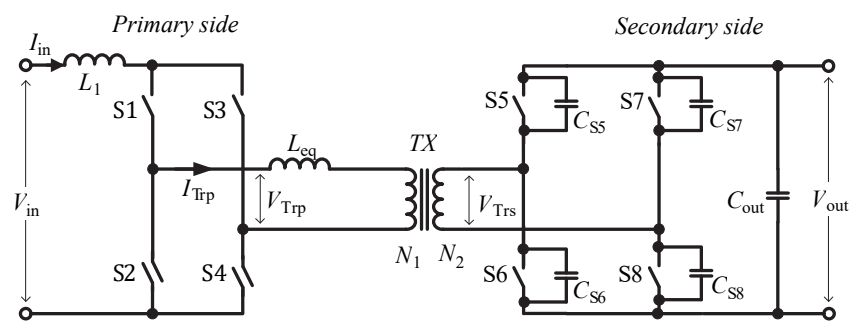

b)

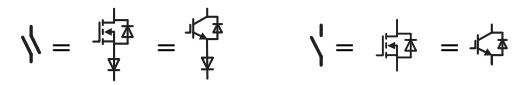

Fig. 1. Topology of the asymmetric converters proposed: ARPC (a), ASMB (b).

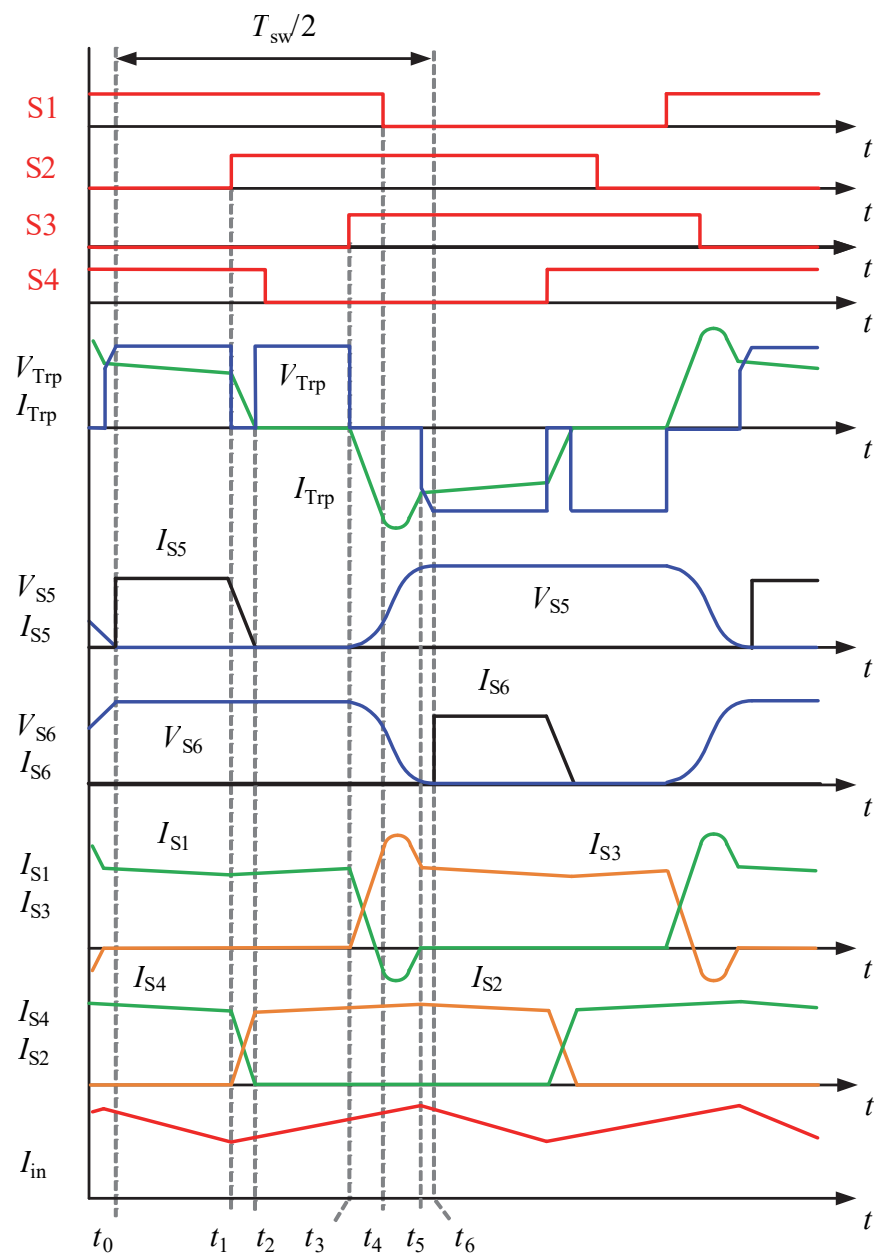

Fig. 2. Idealized operating waveforms of APRC with a passive rectifier.

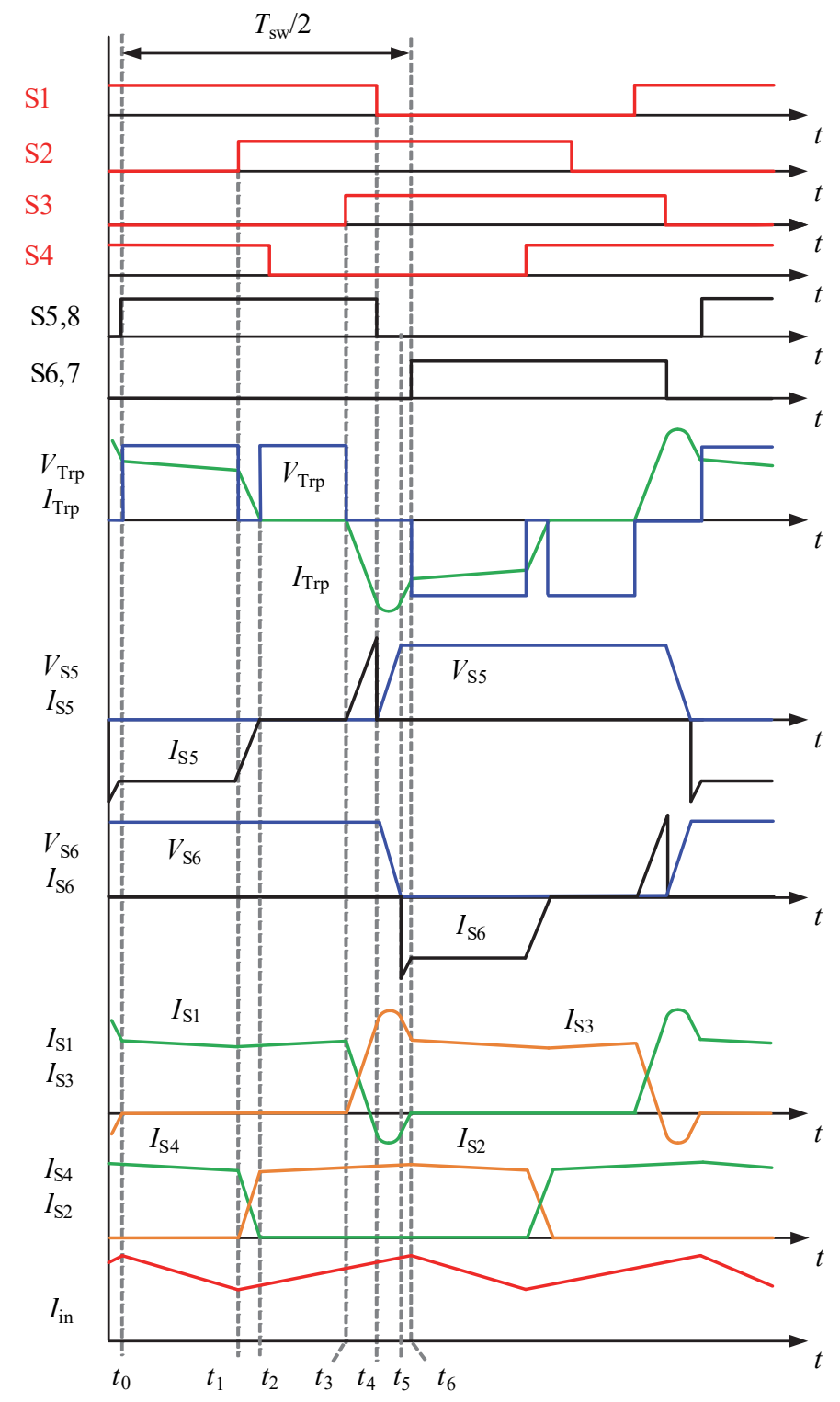

Fig. 3. Idealized operating waveforms of ASMC with an active rectifier. 


\section{DESCRIPTION OF OPERATION}

The converter topologies proposed are shown in Fig. 1. As can be observed, they feature two reverse-conducting and two reverse-blocking devices at the primary side. The asymmetric parallel resonant converter (APRC) topology can be implemented with a passive rectifier (Fig. 1a). It utilizes a resonant tank formed by $L_{\mathrm{eq}}$ and $C_{\mathrm{eq}}$ to redistribute current between the top transistors. The asymmetric secondary modulation-based converter (ASMC) topology in Fig. 1b has an active rectifier that is used to force the currents to change direction and achieve the same goal. The equivalent capacitor across the transformer primary winding can be formed by the intrinsic capacitances of the rectifier switches $\left(C_{\mathrm{S} 5}-C_{\mathrm{S} 8}\right)$ and/or separately. Similarly, the equivalent inductance can represent the leakage inductance of the transformer reflected to the primary winding or by an additional inductor in series to the primary winding. Both topologies operate at a constant switching frequency and regulate output voltage by phase-shift between the top and bottom switches. The operation of the converters presented in Figs. 2 and 3 can be described by six switching modes for each half-period $T_{\mathrm{sw}} / 2$.

\section{A. The APRC Topology}

$t_{0}-t_{1}$ : switches S1 and S4 are turned on and the other ones are turned off. The converter is in the active state and the power is transferred to the output through switches S1, S4 and diodes S5 and S8. At the end of this interval, the input current reaches the minimum value.

$t_{1}-t_{2}: \mathrm{S} 2$ is turned off and the active state is finished. The current of S2 rises, while the current of S4 decreases linearly with $\mathrm{d} i / \mathrm{d} t$, caused by the equivalent leakage inductance. The currents of S5 and S8 as well as the transformer current decrease with the same slope. The input inductor voltage polarity is reversed and its current starts to increase, while the transformer primary voltage is zero.

$t_{2}-t_{3}$ : the current of S2 reaches the input current level and the transformer primary voltage rises to the amplitude value. The converter is in the shoot-through state with S1 and S2 conducting while the input inductor is energized. S4 could be turned off with ZCS.

$t_{3}-t_{4}$ : S3 is turned on and the resonant process is started. Capacitor $\mathrm{C}_{\mathrm{eq}}$ starts to recharge and, as a result, the $\mathrm{S} 1$ current decreases and the S3 current increases (Fig. 2).

$t_{4}-t_{5}$ : when the resonant current becomes higher than the input current, the soft switching condition is satisfied; the body diode of S1 starts to conduct and the transistor channel can be turned off with ZCS. The currents at the primary side reach the amplitude value when the capacitor voltage crosses zero and, as the capacitor $\mathrm{C}_{\mathrm{eq}}$ voltage polarity changes, starts to decrease back to the value of the input current.

$t_{5}-t_{6}$ : the currents at the input side are equal to the input current and the recharging of capacitor $\mathrm{C}_{\mathrm{eq}}$ continues. When $\mathrm{C}_{\text {eq }}$ and the transformer voltages reach the amplitude value, rectifier switches S6 and S7 become forward-biased and start to supply the current to the output. From $t_{6}$ the converter active state starts and the processes are then repeated for another switching half-period.

\section{B. The ASMC Topology}

The first three modes are equivalent to those in APRC.

$t_{0}-t_{1}$ : switches S1 and S4 are turned on and the other ones are turned off. The converter is in the active state and the power is transferred to the output through switches S1, S4 and MOSFETs S5 and S8. At the end of this interval, the input current reaches the minimum value.

$t_{1}-t_{2}: \mathrm{S} 2$ is turned off and the active state is finished. The current of S2 rises, while the current of S4 decreases linearly with $\mathrm{d} i / \mathrm{d} t$, caused by the equivalent leakage inductance. The currents of S5 and S8 as well as the transformer current decrease with the same slope. The input inductor voltage polarity is reversed and its current starts to increase, while the transformer primary voltage is zero.

$t_{2}-t_{3}$ : the current of S2 reaches the input current level and the transformer primary voltage rises to the amplitude value. The converter is in the shoot-through state with S1 and S2 conducting while the input inductor is energized. S4 could be turned off with ZCS.

$t_{3}-t_{4}$ : $\mathrm{S} 3$ is turned on and the current of S3 rises, while the current of $\mathrm{S} 1$ decreases linearly with $\mathrm{d} i / \mathrm{d} t$, caused by equivalent leakage inductance. This mode is analogous to the interval $t_{1}-t_{2}$ (Fig. 3).

$t_{4}-t_{5}$ : since $\mathrm{S} 1$ is a reverse-conducting device, after decreasing to zero, the current starts to flow through its body diode, changing with the same slope, while the current through $\mathrm{S} 3$ rises above the input current. Thus, the soft switching condition is satisfied and S1 can be turned off with ZCS, along with S5 and S8. The equivalent capacitor recharges and the transformer voltage changes its polarity.

$t_{5}-t_{6}$ : capacitor $\mathrm{C}_{\mathrm{eq}}$ is recharged, the transformer secondary voltage reaches the amplitude value and the body diodes of S6 and S7 become forward-biased. The current through S1 returns back to zero with the same $\mathrm{d} i / \mathrm{d} t$, and the current of $\mathrm{S} 3$ and the transformer primary current become equal to the input current. From $t_{6}$, the converter active state is started, hence S6 and $\mathrm{S} 7$ can be turned on to avoid excessive losses in the body diodes. The processes are then repeated for another switching half-period.

\section{C.Design Aspects}

\section{The APRC converter}

For APRC, soft switching is achieved if peak transformer primary current $I_{\mathrm{P}(\mathrm{res})}$ is larger than input inductor current $I_{\text {in }}$.

$$
I_{\mathrm{P}(\mathrm{res})}=\frac{V_{\text {out }}}{n Z_{\mathrm{r}}} \geq I_{\text {in }},
$$

where $V_{\text {out }}$ is the output voltage, $n$ is the transformer turns ratio and $Z_{\mathrm{r}}$ is the impedance of the resonant circuit:

$$
Z_{\mathrm{r}}=\sqrt{\frac{L_{\mathrm{eq}}}{C_{\mathrm{eq}}}},
$$

where $L_{\text {eq }}$ is the inductance of the equivalent circuit (largely determined by transformer leakage inductance) and $C_{\text {eq }}$ is the equivalent capacitance, which can be represented by the intrinsic capacitance of the rectifier semiconductor and/or an external capacitor. 
To satisfy the soft switching criteria for a wide range of conditions, the resonant circuit should be designed around minimal input voltage at full load. The required impedance of the resonant tank $Z_{\mathrm{r}}$, should be chosen according to

$$
Z_{\mathrm{r}}=\sqrt{\frac{L_{\text {eq }}}{C_{\text {eq }}}} \leq \frac{V_{\text {out }}}{n I_{\mathrm{P}(\mathrm{res})}}=\frac{V_{\text {in }(\min )} V_{\text {out }}}{n P_{\max }},
$$

where $P_{\max }$ is the maximum power of the converter. The required resonant frequency is estimated by

$$
f_{\mathrm{r}}=\frac{f_{\mathrm{sw}}}{1-\frac{n}{G_{\min }}},
$$

where $f_{\text {sw }}$ is the converter switching frequency and $G_{\min }$ is the desired minimum converter voltage gain. The resonant frequency is calculated from

$$
f_{\mathrm{r}}=\frac{1}{2 \pi \sqrt{L_{\mathrm{eq}} C_{\mathrm{eq}}}} .
$$

From (3)-(5), the equation for the required equivalent inductance $L_{\text {eq }}$ is obtained from

$$
L_{\mathrm{eq}}=\frac{Z_{\mathrm{r}}}{2 \pi f_{\mathrm{r}}} .
$$

The associated resonant capacitance can then be derived from (3).

The duty cycle of the switches should be higher than 0.5 to avoid open circuit of the input inductor and for S2 and S4, it can be approximated as

$$
D_{\mathrm{S} 2, \mathrm{~S} 4}^{\min } \geq \frac{1}{2}+\frac{n L_{\mathrm{eq}} P_{\max }}{V_{\text {in }} V_{\text {out }}} .
$$

For the other pair of switches (S1 and S3), the required duty cycle is estimated from

$$
D_{\mathrm{S} 1, \mathrm{~S} 3}=\frac{1}{2}+\frac{f_{\mathrm{sw}}}{4 f_{\mathrm{r}}} .
$$

The gain of this converter is not sensitive to load variations and is estimated from

$$
G=\frac{n}{1-f_{\mathrm{sw}}\left(\frac{1}{f_{\mathrm{r}}}+2 t_{2-3}\right)} .
$$

\section{The ASMB Converter}

For the ASMB converter, the duty cycle of the switches can be calculated from (8) for the minimum possible input voltage and the maximum power level. It should be noticed that a longer duty cycle would lead to an increased peak current at the primary side and excessive energy circulation. In the ideal case, the peak current of the converter should be equal to maximum possible input current $I_{\text {in(max) }}$, and the switch duty cycle is obtained by

$$
D=\frac{1}{2}+\frac{n I_{\text {in }(\max )} L_{\mathrm{eq}} f_{\mathrm{sw}}}{V_{\text {out }}},
$$

where $I_{\text {in }(\max )}=P_{\max } / V_{\text {in(min) }}$.
The minimum total duration of the shoot-through state $\left(t_{1}-t_{6}\right)$ is then estimated from

$$
t_{1-6(\min )}=\frac{2\left[L_{\mathrm{eq}}\left(n I_{\mathrm{in}(\max )}\right)^{2}+C_{\mathrm{eq}} V_{\text {out }}^{2}\right]}{n I_{\text {in }(\max )} V_{\text {out }}} .
$$

As shown, both $L_{\text {eq }}$ and $C_{\text {eq }}$ increase the resulting minimum duration of the shoot-through state. Therefore, they should be carefully selected to have the desired regulation capabilities of the converter. The converter gain can be then estimated from

$$
G=\frac{1}{1-2 f_{\mathrm{sw}}\left(t_{2-3}+t_{1-6(\min )}\right)} .
$$

\section{Generalizations}

Unlike in other topologies with phase shift control, the peak current of the top transistors is higher than the input current, which offers a specific advantage. From the operational waveforms and equations presented it follows that the recharging of capacitor $C_{\text {eq }}$ takes place when the current is at its peak value, which is higher than the maximum input current. Thus, the capacitor recharge time is constant and unaffected by the converter operating point and operation at light load does not affect converter gain or require adjustments to the control strategy. Since only top transistors exhibit such an increased current, the total energy circulation through semiconductors at low-load conditions can be lower than that of the topologies with symmetric control. While the APRC topology requires lesser number of active switches, the ASMB provides a larger degree of freedom when choosing the value of $C_{\text {eq. }}$. Moreover, if the input current value is known, the implementation of digital control to adjust the duty cycles of the switches would allow a significant reduction of the circulating energy.

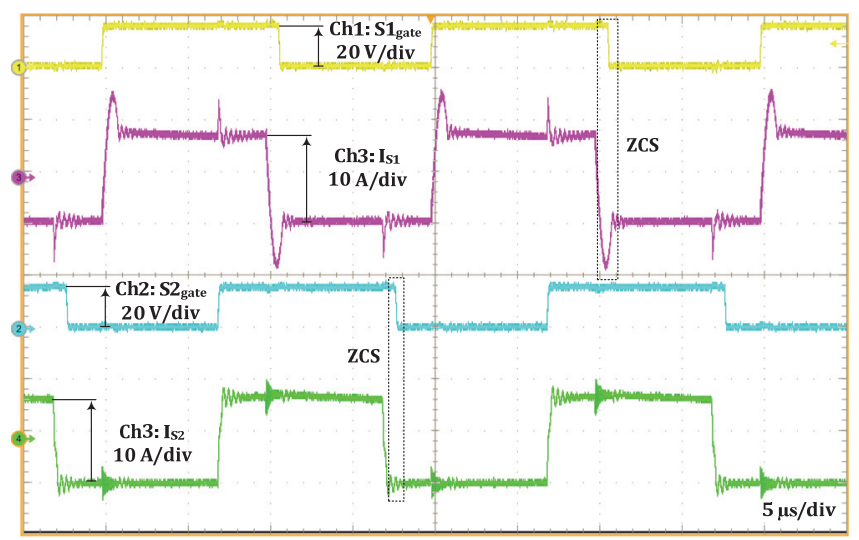

Fig. 4. Experimental waveforms of an APRC converter: Ch1 - S1 gate voltage, $\mathrm{Ch} 2-\mathrm{S} 2$ gate voltage, $\mathrm{Ch} 3-\mathrm{S} 1$ current and $\mathrm{Ch} 4-\mathrm{S} 2$ current. 


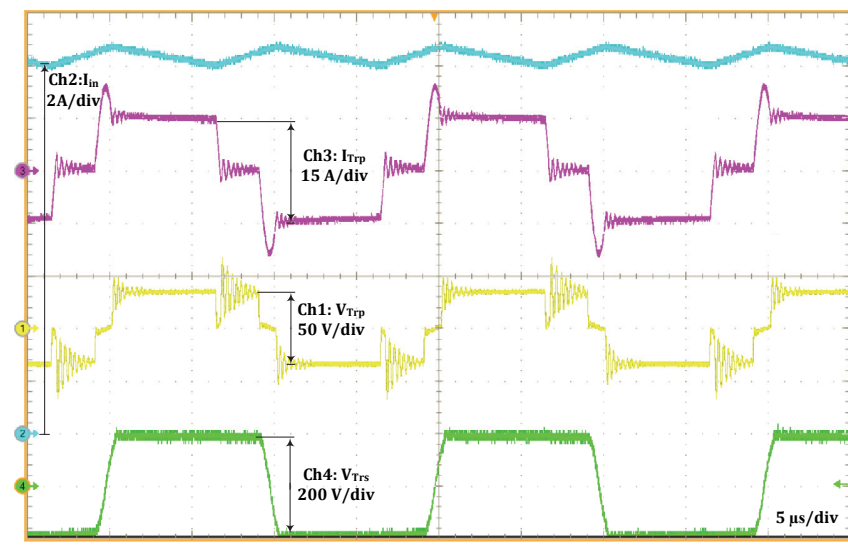

Fig. 5. Experimental waveforms of an APRC converter: Ch1 $-V_{\operatorname{Trp}}, \mathrm{Ch} 2-I_{\text {in }}$, $\mathrm{Ch} 3-I_{\mathrm{Trp}}$ and $\mathrm{Ch} 4-V_{\mathrm{Trs}}$.

\section{EXPERIMENTAL VERIFICATION}

To validate the proposed converters, an experimental prototype with a rated power of $400 \mathrm{~W}$ was assembled and both topologies were tested with the same hardware. Synchronous MOSFETs instead of series diodes were applied in the primary part to reduce conduction losses. The parameters and components used are listed in Table I.

TABLE I

PARAMETERS AND COMPONENTS OF THE EXPERIMENTAL PROTOTYPE

\begin{tabular}{|l|c|c|}
\hline \multicolumn{1}{|c|}{ Parameter/component } & Symbol & Value \\
\hline Input voltage, DC & $V_{\text {in }}$ & $20-30 \mathrm{~V}$ \\
\hline Output voltage, DC & $V_{\text {out }}$ & $400 \mathrm{~V}$ \\
\hline Switching frequency & $f_{\text {sw }}$ & $50 \mathrm{kHz}$ \\
\hline Primary side inductors inductance & $L_{1}$ & $100 \mu \mathrm{H}$ \\
\hline $\begin{array}{l}\text { Equivalent capacitance (at TX primary } \\
\text { winding) }\end{array}$ & $C_{\mathrm{eq}}$ & $10 \mathrm{nF}$ \\
\hline Transformer turns ratio & $N_{2} / N_{1}$ & $13: 1$ \\
\hline Equivalent TX leakage inductance & $L_{\mathrm{eq}}$ & $0.8 \mu \mathrm{H}$ \\
\hline Rated power & $P_{\text {rated }}$ & $400 \mathrm{~W}$ \\
\hline Primary-side transistors & $\mathrm{S} 1-\mathrm{S} 4$ & FDMS86181 \\
\hline Secondary-side transistors & $\mathrm{S} 5-\mathrm{S} 8$ & STP18N60DM2 \\
\hline Microcontroller & - & STM32F334R8T6 \\
\hline Primary-side transistor drivers & - & ADUM3221 \\
\hline Secondary-side transistor drivers & - & ACPL-P346 \\
\hline
\end{tabular}

The experimental waveforms for the APRC topology at $V_{\text {in }}=24 \mathrm{~V}$ are presented in Figs. 4 and 5. As shown in Fig. 4, top switch $\mathrm{S} 1$ is turned off when the resonant current is flowing through its body diode, resulting in ZCS. Bottom switch S2 is turned off when its current is taken over by S4, which also results in ZCS. All the primary switches turn on with reduced $\mathrm{d} i / \mathrm{d} t$ and, as a result, the turn-on losses diminish. The input current waveform in Fig. 5 shows that the converter continues to be in the shoot-through state during the resonant period, while the transformer secondary winding changes polarity.

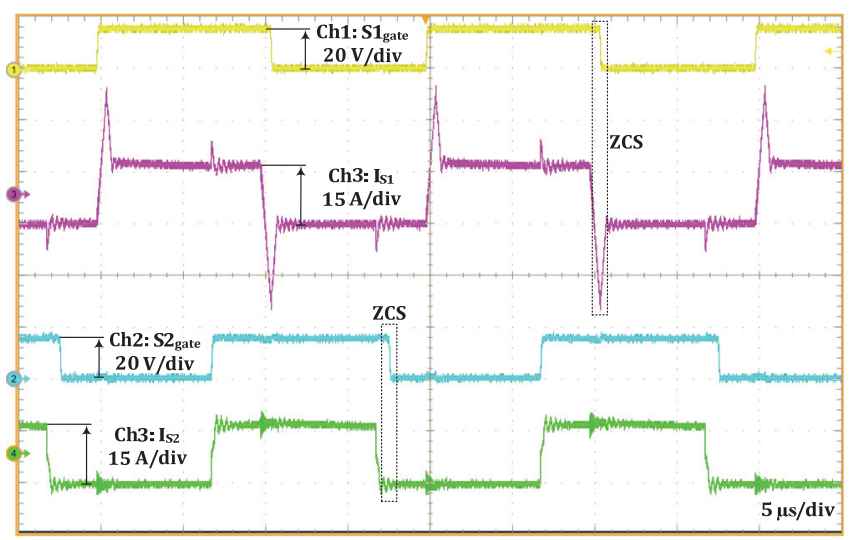

Fig. 6. Experimental waveforms of an ASMC converter: Ch1 - S1 gate voltage, Ch2 - S2 gate voltage, Ch3 - S1 current and Ch4 - S2 current.

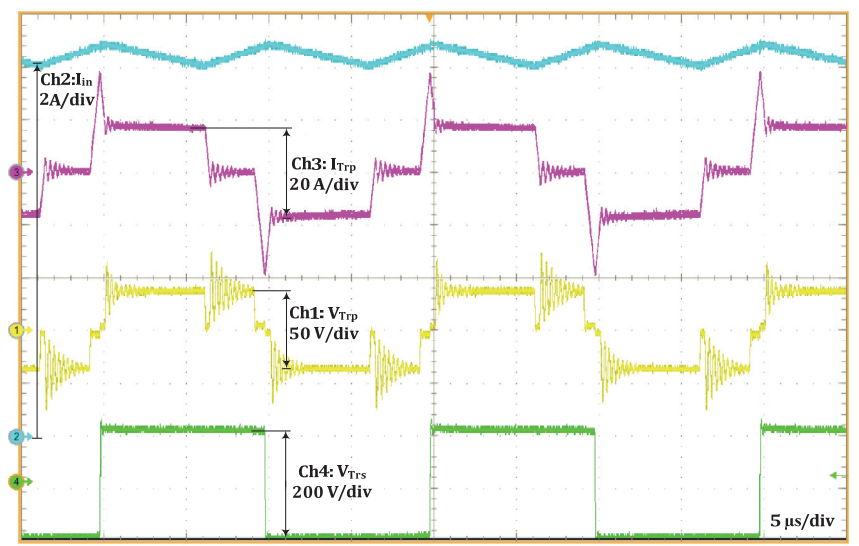

Fig. 7. Experimental waveforms of an ASMC converter: $\mathrm{Ch} 1-V_{\mathrm{Trp}}, \mathrm{Ch} 2-I_{\text {in }}$, $\mathrm{Ch} 3-I_{\mathrm{Trp}}$ and $\mathrm{Ch} 4-V_{\mathrm{Trs}}$.

The measurement results of ASMC at $V_{\text {in }}=24 \mathrm{~V}$ are shown in Figs. 6 and 7. During the experiments, the converter was operating with a very small value of $C_{\text {eq }}$ and, as a result, the $t_{4}-t_{5}$ interval is minor. Similar to the APRC topology, the top transistors turn off when their body diode conducts, while the bottom ones - after the current drops to zero, resulting in ZCS for all the primary semiconductors. From Fig. 7 it can be observed that the transformer secondary voltage changes polarity when its current is at the peak value and, since $C_{\mathrm{eq}}$ could be small for this converter, the process takes significantly less time. During the laboratory experiments, the power stage of ARPC reached an efficiency of $96.4 \%$ and that of ASMC - $96.6 \%$ at an input voltage of $30 \mathrm{~V}$.

The experimental results are in agreement with theoretical estimations for both topologies and therefore it can be concluded that the claims presented in the previous sections have been confirmed. 


\section{CONCLUSION}

This paper introduced two isolated soft-switching asymmetric current-fed DC-DC converters with a passive rectifier and an active one. The proposed topologies can be applied in systems where a high gain and/or galvanic isolation are required, such as fuel cells, batteries, DC microgrids and other applications. The converters have two reverse-blocking devices and two reverse-conducting ones at the primary side and utilize phase-shift control with a constant switching frequency. Their main aim is to reduce the problem of high circulating energy encountered in existing symmetric topologies and the high conduction losses present in topologies with phase-shift control.

The experimental results showed a peak power stage efficiency of $96.4 \%$ and $96.6 \%$ for the ARPC and ASMC topologies, respectively. That proves that the topologies proposed allow achieving a comparable level of efficiency while having a lower switch count than other existing topologies with a phase-shift control algorithm and lower current stress than the topologies with a symmetrical modulation control algorithm.

Future research will focus on the detailed analysis of the presented topologies and their comparison with other existing solutions, designed with the same constraints and requirements.

\section{ACKNOWLEDGEMENT}

This research was supported by the Estonian Centre of Excellence in Zero Energy and Resource Efficient Smart Buildings and Districts, ZEBE, grant 2014-2020.4.01.15-0016 funded by the European Regional Development Fund.

\section{REFERENCES}

[1] D. Kumar, F. Zare, and A. Ghosh, "DC Microgrid Technology: System Architectures, AC Grid Interfaces, Grounding Schemes, Power Quality, Communication Networks, Applications, and Standardizations Aspects," IEEE Access, vol. 5, pp. 12230-12256, 2017. https://doi.org/10.1109/access.2017.2705914

[2] A. Kwasinski, "Quantitative Evaluation of DC Microgrids Availability: Effects of System Architecture and Converter Topology Design Choices," IEEE Transactions on Power Electronics, vol. 26, no. 3, pp. 835-851, Mar. 2011.

[3] G. Tibola and J. L. Duarte, "Isolated Bidirectional DC-DC Converter for Interfacing Local Storage in Two-Phase DC Grids," in 2017 IEEE 8th International Symposium on Power Electronics for Distributed Generation Systems (PEDG), Florianopolis, 2017, pp. 1-8. https://doi.org/10.1109/pedg.2017.7972440

[4] B. Zhao, Q. Yu, and W. Sun, "Extended-Phase-Shift Control of Isolated Bidirectional DC-DC Converter for Power Distribution in Microgrid," IEEE Transactions on Power Electronics, vol. 27, no. 11, pp. 46674680, Nov. 2012. https://doi.org/10.1109/tpel.2011.2180928

[5] G. Xu, D. Sha, Y. Xu and X. Liao, "Dual-Transformer-Based DAB Converter With Wide ZVS Range for Wide Voltage Conversion Gain Application," IEEE Transactions on Industrial Electronics, vol. 65, no. 4, pp. 3306-3316, April 2018.

[6] V. Karthikeyan and R. Gupta, "FRS-DAB Converter for Elimination of Circulation Power Flow at Input and Output Ends," IEEE Transactions on Industrial Electronics, vol. 65, no. 3, pp. 2135-2144, Mar. 2018. https://doi.org/10.1109/tie.2017.2740853
[7] D. B. W. Abeywardana, B. Hredzak, and V. G. Agelidis, "Single-Phase Grid-Connected $\mathrm{LiFePO}_{4}$ Battery-Supercapacitor Hybrid Energy Storage System With Interleaved Boost Inverter," IEEE Transactions on Power Electronics, vol. 30, no. 10, pp. 5591-5604, Oct. 2015. https://doi.org/10.1109/tpel.2014.2372774

[8] X. Sun, X. Wu, Y. Shen, X. Li, and Z. Lu, "A Current-Fed Isolated Bidirectional DC-DC Converter," IEEE Transactions on Power Electronics, vol. 32, no. 9, pp. 6882-6895, Sept. 2017.

[9] M. Ryu, D. Jung, J. Baek, and H. Kim, "An Optimized Design of BiDirectional Dual Active Bridge Converter for Low Voltage Battery Charger," in 2014 16th International Power Electronics and Motion Control Conference and Exposition, Antalya, 2014, pp. 177-183. https://doi.org/10.1109/epepemc.2014.6980709

[10] L. Zhu, "A Novel Soft-Commutating Isolated Boost Full-Bridge ZVSPWM DC-DC Converter for Bidirectional High Power Applications," IEEE Transactions on Power Electronics, vol. 21, no. 2, pp. 422-429, Mar. 2006. https://doi.org/10.1109/tpel.2005.869730

[11] R. Watson and F. C. Lee, "A Soft-Switched, Full-Bridge Boost Converter Employing an Active-Clamp Circuit," in PESC Record. 27th Annual IEEE Power Electronics Specialists Conference, Baveno, 1996, vol. 2, pp. 1948-1954. https://doi.org/10.1109/pesc.1996.548847

[12] R. Y. Chen, T. J. Liang, J. F. Chen, R. L. Lin, and K. C. Tseng, "Study and Implementation of a Current-Fed Full-Bridge Boost DC-DC Converter With Zero-Current Switching for High-Voltage Applications," IEEE Transactions on Industry Applications, vol. 44, no. 4, pp. 1218-1226, 2008. https://doi.org/10.1109/tia.2008.926056

[13] P. Xuewei and A. K. Rathore, "Novel Bidirectional Snubberless Naturally Commutated Soft-Switching Current-Fed Full-Bridge Isolated DC/DC Converter for Fuel Cell Vehicles," IEEE Transactions on Industrial Electronics, vol. 61, no. 5, pp. 2307-2315, May 2014. https://doi.org/10.1109/tie.2013.2271599

[14] C. Iannello, S. Luo, and I. Batarseh, "Full Bridge ZCS PWM Converter for High-Voltage High-Power Applications," IEEE Transactions on Aerospace and Electronic Systems, vol. 38, no. 2, pp. 515-526, Apr. 2002. https://doi.org/10.1109/taes.2002.1008983

[15] A. Mohammadpour, L. Parsa, M. H. Todorovic, R. Lai, R. Datta, and L. Garces, "Series-Input Parallel-Output Modular-Phase DC-DC Converter With Soft-Switching and High-Frequency Isolation," IEEE Transactions on Power Electronics, vol. 31, no. 1, pp. 111-119, Jan. 2016. https://doi.org/10.1109/tpel.2015.2398813

[16] A. Blinov, D. Vinnikov, and V. Ivakhno, "Full Soft-Switching High Step-Up DC-DC Converter for Photovoltaic Applications," in 2014 16th European Conference on Power Electronics and Applications, Lappeenranta, Finland, 2014, pp. 1-7. https://doi.org/10.1109/epe.2014.6911013

[17] A. Chub, R. Kosenko, A. Blinov, V. Ivakhno, V. Zamaruiev, and B. Styslo, "Full Soft-Switching Bidirectional Current-Fed DC-DC Converter," in 56th International Scientific Conference on Power and Electrical Engineering of Riga Technical University (RTUCON), Riga, 2015, pp. 189-194. https://doi.org/10.1109/rtucon.2015.7343149

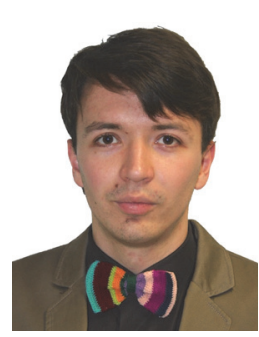

Roman Kosenko (S'14) received the Dipl. Eng. and M. sc. degrees in Electronics from the Department of Industrial Electronics, Chernihiv State University of Technology, Chernihiv, Ukraine, in 2011 and 2013, respectively.

He is currently working toward the $\mathrm{Ph}$. $\mathrm{D}$. degree at the Power Electronics Group, Department of Electrical Power Engineering and Mechatronics, Tallinn University (Estonia), and at the Biomedical Radioelectronic Apparatus and Systems Department of Chernihiv National University of Technology (Ukraine). His fields of interest include research, design and simulation of switch mode converters for distributed power generation systems. He is author or co-author of 25 scientific papers and is the holder of three utility models in the field of power electronics. E-mail: roman.kosenko@ttu.ee ORCID iD: https://orcid.org/0000-0002-6214-3790 


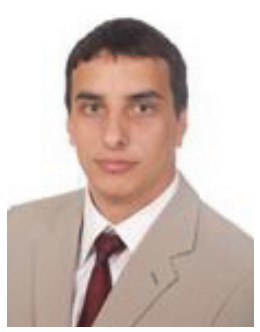

Andrei Blinov received the B. sc. and M. sc. degrees in electrical drives and power electronics and the $\mathrm{Ph}$. D. degree, with a dissertation devoted to the research of switching properties and performance improvement methods of high-voltage IGBT-based DC-DC converters, from Tallinn University of Technology, Tallinn, Estonia, in 2005, 2008, and 2012, respectively. $\mathrm{He}$ is currently a Senior Researcher at the Department of Electrical Engineering, Tallinn University of Technology. His research interests are in modelling and research of switch-mode power converters, advanced modulation techniques, new power semiconductor device technologies and semiconductor heat dissipation aspects.

E-mail: andrei.blinov@ieee.org

ORCID iD: https://orcid.org/0000-0001-8577-4897

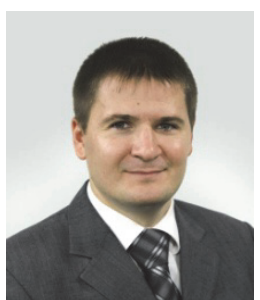

Dmitri Vinnikov (M'07-SM'11) received the Dipl. Eng., M. sc., and Dr. sc. techn. degrees in electrical engineering from Tallinn University of Technology, Tallinn, Estonia, in 1999, 2001, and 2005 , respectively.

$\mathrm{He}$ is currently the Head of the Power Electronics Group, Department of Electrical Power Engineering and Mechatronics, Tallinn University of Technology, and a Guest Researcher at the Institute of Industrial Electronics and Electrical Engineering, Riga Technical University. He has authored more than 200 published papers on power converter design and development and is the holder of numerous patents and utility models in this field. His research interests include impedance-source power converters, modelling and simulation of power systems, applied design of power converters and control systems, and implementation of wide bandgap semiconductors.

E-mail: dmitri.vinnikov@gmail.com

ORCID iD: https://orcid.org/0000-0001-6010-3464

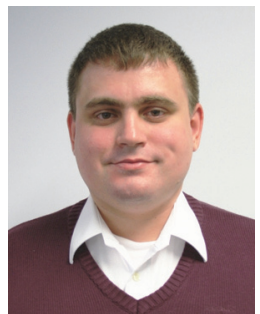

Andrii Chub (S'12-M'17) received the B. sc. degree in Electronics and the M.sc. degree in Electronic Systems from Chernihiv State Technological University, Chernihiv, Ukraine, in 2008 and 2009, respectively. He is currently pursuing the $\mathrm{Ph}$. D. degree at the Power Electronics Group, Tallinn University of Technology.

$\mathrm{He}$ is currently a Guest Researcher at the Chair of Power Electronics, Faculty of Engineering, Christian Albrechts University of Kiel (Germany). He has coauthored more than 40 papers and one book chapter on power electronics and its applications. His research interests include DC-DC converters, DC-AC inverters, impedance source electric energy conversion technology, implementation of the new wide-bandgap semiconductors in power electronic converters, and control of renewable energy conversion systems.

E-mail: andrii.chub@ieee.org

ORCID iD: https://orcid.org/0000-0002-4253-7506 